\title{
MicroRNA-466 with tumor markers for cervical cancer screening
} \\ ${ }^{1}$ Department of Clinical Laboratory, Affiliated Cancer Hospital of Zhengzhou University \& Henan Cancer Hospital, Zhengzhou, \\ Henan, China \\ ${ }^{2}$ Department of Clinical Laboratory, Second Affiliated Hospital of Zhengzhou University, Zhengzhou, Henan, China \\ *These authors have contributed equally to this work
}

Correspondence to: Li-Li Zhou, email: zhoulilimy@126.com

Keywords: microRNA-466, cervical cancer, tumor marker, screening, diagnoses

Received: June 20,2017 Accepted: July 13,2017 Published: August 07, 2017

Copyright: Zhou et al. This is an open-access article distributed under the terms of the Creative Commons Attribution License 3.0 (CC BY 3.0), which permits unrestricted use, distribution, and reproduction in any medium, provided the original author and source are credited.

\section{ABSTRACT}

Cervical cancer is the second most common cancer in women in the world. In this study, we explore tumor markers and microRNA-466 combination for cervical cancer screening. Tumor markers were measured by the methods of electrochemiluminescent immunoassay and enzyme immunoassay. The microRNA-466 was performed by quantitative real-time polymerase chain reaction. Among normal group, hyperplasia group and cancer group, the CEA expression levels were $2.26 \mathrm{ng} / \mathrm{ml}, 3.85$ $\mathrm{ng} / \mathrm{ml}$ and $16.08 \mathrm{ng} / \mathrm{ml}$, respectively. While the CA125 expression levels were 13.61 $\mathrm{u} / \mathrm{ml}, 27.32 \mathrm{u} / \mathrm{ml}$ and $44.93 \mathrm{u} / \mathrm{ml}$, respectively. The SCCA expression levels were $13.61 \mathrm{ng} / \mathrm{ml}, 27.32 \mathrm{ng} / \mathrm{ml}$ and $44.93 \mathrm{ng} / \mathrm{ml}$, respectively. The expression levels of tumor markers were all gradually increased with the development of cervical lesions. The expression levels of microRNA-466 in cervical cancers $(0.62)$ were greater than that in normal (0.076) and hyperplasia (0.24). The expression of microRNA-466 was correlated with lymphnode metastasis $(P=0.000)$. There is a lower overall survival rate of patient with large tumor or lymphnode metastasis. Thus, the combination of tumor markers and microRNA-466 can be useful for early detection of cervical cancer and indicators for advanced stage and prognosis of the disease.

\section{INTRODUCTION}

Cervical cancer is the second most frequent cancer in women and the most common gynecological cancer [1]. In 2008, there were about 529,800 cases included 275,000 deaths worldwide due to cervical cancer [2]. Moreover, $85 \%$ of new cases occur in developing countries where the survival rates are substantially lower as a result of a presentation at relatively advanced stages [3]. This condition affects severely the health and lives with the women [4].

MicroRNAs (miRNAs), small non-coding short RNAs of 18-25 nucleotides in length, generally act as negative regulators of gene expression at the posttranscriptional level through mRNA degradation or translation repression $[5,6]$. These molecules, as key regulators of cellular growth and differentiation, play an important role in many biological processes $[7,8]$. MicroRNAs were generally down-regulated or upregulated in malignant tissues $[9,10]$. The expression levels of MicroRNA-466 in cervical cancer tissue have been reported in our previous study [11].

Tumor markers, which are small-molecule matters produced by tumor cells or generated by host cells in response to the tumor, are frequently used for screening and monitoring in oncology $[12,13]$. However, the same tumors can express several different unique antigens [13, 14]. Recently, normal cervical cells have been reported to synthesize and secrete the tumor marker carcinoembryonic antigen (CEA) as a frequent constituent of normal cervical mucus [15]. The cancer antigen 125 (CA125), a transmembranes glycoprotein, is a tumor marker mainly utilized for the diagnosis and treatment of epithelial ovarian cancer and cervical cancer [16]. Squamous cell 
carcinoma antigen (SCCA) is separated from a squamous cell carcinoma (SCC) of the uterine cervix [13]. These results suggest that cervical adenocarcinoma may excrete elevated levels of CEA and/or SCCA in cervical cancer instead of CA125. Therefore, we measured tumor markers (CEA, CA125, and SCCA) and MicroRNA-466 in the serum levels from women with or without cervical cancer, and analyzed the results to clarify whether it helps in the early diagnosis of cervical cancer or not.

\section{RESULTS}

\section{The expression levels of tumor markers and microRNA-466}

A total of 735 patients were enrolled in this study, including 245 cervical cancer patients, 280 cervical hyperplasia patients and 210 normal people. The expression levels of CEA in the normal group, hyperplasia group and cancer group were $2.26 \mathrm{ng} / \mathrm{ml}, 3.85 \mathrm{ng} / \mathrm{ml}$ and $16.08 \mathrm{ng} / \mathrm{ml}$, respectively (Figure 1A). It was shown that the expression levels of CEA were gradually built up over the development of cervical lesions. The expression levels of CA125 in three groups were $13.61 \mathrm{u} / \mathrm{ml}, 27.32 \mathrm{u} / \mathrm{ml}$ and $44.93 \mathrm{u} / \mathrm{ml}$, respectively (Figure 1B). Similarly, expression levels of SCCA were $13.61 \mathrm{ng} / \mathrm{ml}, 27.32 \mathrm{ng} / \mathrm{ml}$ and 44.93 $\mathrm{ng} / \mathrm{ml}$, respectively (Figure $1 \mathrm{C}$ ). The increased trend of CA125 and SCCA was similar with CEA.

We tested serum expression levels of microRNA-466 by quantitative real-time PCR in cervical cancer group, hyperplasia group and normal group. It can be seen that significant differences existed in the MicroRNA-466 expression level from the three groups (Figure 2). The averages fold changes of MicroRNA-466 in patients with cervical cancer group and normal group were 0.62 and 0.076 , respectively $(P<0.01)$, and that in patients with hyperplasia group and people group was 0.24 and 0.076 , respectively $(P<0.01)$.
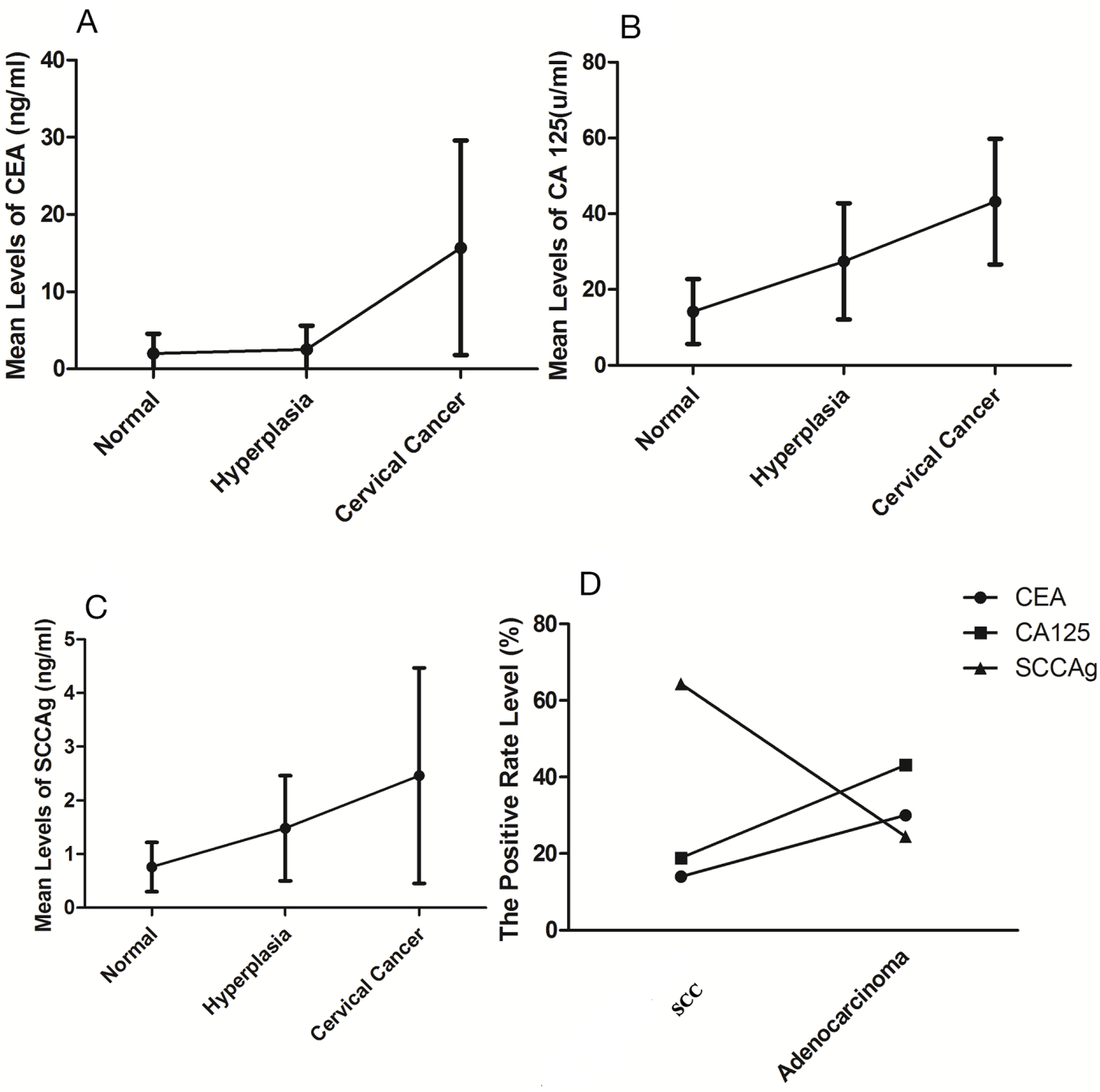

Figure 1: The expression levels of tumor markers. (A) Mean expression levels of CEA in the three groups. (B) Mean expression levels of CA125 in the three groups. (C) Mean expression levels of SCCA in the three groups. (D) The positive rate level of tumor markers between SCC and cervical adenocarcinoma. 
Table 1: The primer sequences of real-time PCR for microRNA-466

\begin{tabular}{cccc}
\hline \multicolumn{1}{c}{ Primer } & Sequences & Product \\
\hline miR-466 & RT stem-loop primer & 5'-GTCGTATCCAGTGCAGGGTCCGAGGTATTCGCACTGGATACGACATGTGTGT-3' & 57 \\
& Forward primer & 5'-ATGGTTCGTGGGATACACATACACGCA-3' \\
Reverse primer & 5'-GCAGGGTCCGAGGTATTC-3' \\
U6 & RT primer & 5'-CGCTTCACGAATTTGCGTGTCAT-3' & 101 \\
& Forward primer & 5'-GCTTCGGCAGCACATATACTAAAAT-3' \\
Reverse primer & 5'-CGCTTCACGAATTTGCGTGTCAT-3' \\
\hline
\end{tabular}

\section{The expression levels of microRNA-466 in cervical cancer patients}

There were 245 cervical cancer patients, including 143 squamous cell carcinoma (SCC) patients and 102 adenocarcinomas (AC) patients. Cervical cancer patients' characteristics were described in Table 1. There was no significant difference in age, the international federation of gynecology and obstetrics (FIGO), and tumor size between the SCC patients and AC patients $(P=0.076)$. However, AC was more prone to lymph node metastasis than SCC $(P=0.039)$. Interestingly, microRNA-466 expression was likewise higher in the lymph node metastatic than in the negative lymph node $(P=0.000)$.

SCCA was raised in $63.8 \%$ of SCC patients at diagnosis (Figure 1D). Levels of CEA and CA125 in SCC patients were elevated in $14.3 \%$ and $18.9 \%$, respectively. However, CA125 was preeminent in $43.1 \%$ of AC patients at diagnosis. Levels of CEA and SCCA of AC patients were only elevated in $29.2 \%$ and $21.6 \%$, respectively.

\section{Overall survival curves for cervical cancer}

The median overall survival was 32.6 months $(95 \%$ CI, 7 months to not estimable). Compared to the patient with small tumor $(\leq 4 \mathrm{~cm})$, there is a low overall survival rate of patient with large tumor $(>4 \mathrm{~cm})$ (Figure $3 \mathrm{~A})$. The overall survival rate of patient with lymphnode metastasis is lower than patient without lymphnode metastasis (Figure 3B). There was a significant difference.

\section{AUC for diagnosing cervical cancer}

It showed the AUC values of preoperative tumor markers and microRNA-466 for predicting high-risk factors in the training set (Table 2). The estimated logistic regression model on receiver operating curves (ROC) analysis was utilized. We used c-statistics to calculate the AUC of the ROC. The AUC of the combination was shown in Table 3. The combination of tumor markers and microRNA-466 can be a better diagnosis of cervical cancer $(\mathrm{AUC}=0.85)$.

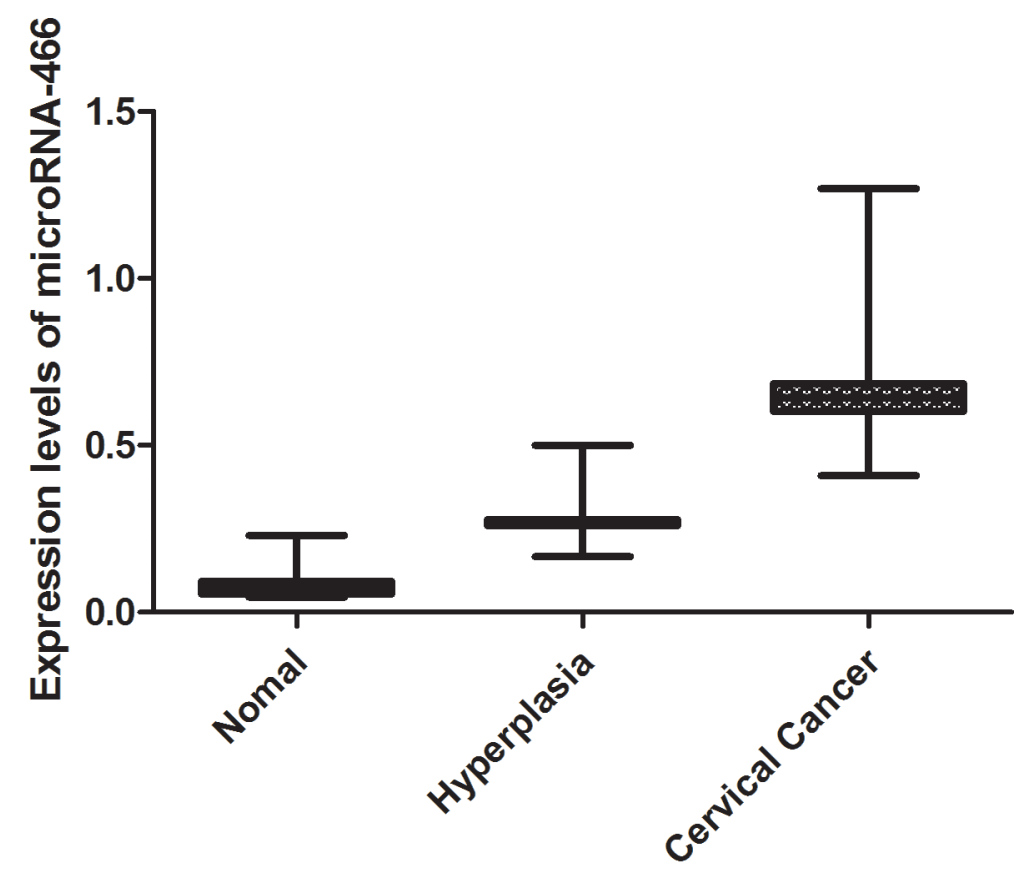

Figure 2: The expression levels of microRNA-466. 
Table 2: Clinical characteristics of 245 cervical cancer patients

\begin{tabular}{|c|c|c|c|c|c|}
\hline Characteristics & $\begin{array}{c}\operatorname{SCC}(\%) \\
n=143\end{array}$ & $\begin{array}{c}\mathrm{AC}(\%) \\
n=102\end{array}$ & $P^{a}$ Value & $\begin{array}{c}\text { Expression of MiR- } \\
466 \\
(\mathrm{M} \pm \mathrm{SEM})\end{array}$ & $P^{\text {a }}$ Value \\
\hline \multicolumn{6}{|l|}{ Age (years) } \\
\hline$\leq 50$ & $59(42.3)$ & $45(44.1)$ & 0.695 & $0.616 \pm 0.151$ & 0.733 \\
\hline$>50$ & $84(58.7)$ & 57 (55.9) & & $0.623 \pm 0.164$ & \\
\hline \multicolumn{6}{|l|}{ FIGO stage } \\
\hline I, IIa & $92(64.3)$ & $68(66.7)$ & 0.706 & $0.612 \pm 0.147$ & 0.219 \\
\hline IIb, III-IV & $51(35.7)$ & $34(33.3)$ & & $0.635 \pm 0.123$ & \\
\hline \multicolumn{6}{|l|}{ Tumor size } \\
\hline$\leq 4 \mathrm{~cm}$ & $104(72.7)$ & $70(68.6)$ & 0.486 & $0.609 \pm 0.160$ & 0.076 \\
\hline$>4 \mathrm{~cm}$ & $39(27.3)$ & $32(31.4)$ & & $0.647 \pm 0.128$ & \\
\hline \multicolumn{6}{|l|}{ Lymph node } \\
\hline Negative & $106(74.1)$ & $63(61.8)$ & 0.039 & $0.582 \pm 0.197$ & 0.000 \\
\hline Positive & 37 (25.9) & $39(38.2)$ & & $0.705 \pm 0.178$ & \\
\hline
\end{tabular}

SCC: squamous cell carcinoma; AC: adenocarcinoma;

FIGO: International Federation of Gynecology and Obstetrics.

a Student's t test.

\section{DISCUSSION}

Cervical cancer which is the second most common cancer in women has become a major-health care problem throughout the world [1]. The 5-year survival rate is only $38 \%$ to $56 \%$ for an advanced stage [17]. Therefore, it is important to diagnose cervical cancer at an early stage. Tumor markers have been widespread used in clinical medicine [18, 19]. Tumor markers can offer early diagnosis, prognosis evaluation and therapeutic efficacy evaluation [20].

CEA was first identified in the serum of patients with colonic carcinoma [21]. Several studied to have

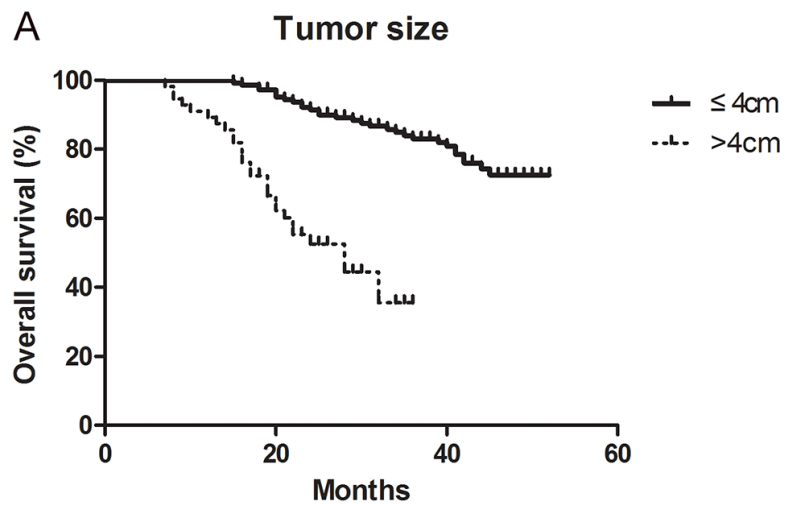

shown CEA was positivity in an abdominal tumor, including cervical cancer $[22,23]$. CA 125, produced by epithelial ovarian tumors, has been put forward as a tumor marker of ovarian cancer [24]. CA125 can be also expressed in cervical glands [16]. Recently, normal cervical glandular cells have been recorded to synthesize and secrete the tumor marker CA 125 into normal cervical mucus $[16,25]$. Numerous studies have shown SCCA levels were correlation with the high-risk factors in early stage of SCC $[13,26]$. In our study, we showed that the expression levels of CEA, CA125 and SCCA were all gradually increased by the development of cervical lesions. The expression levels of CEA and CA125 were

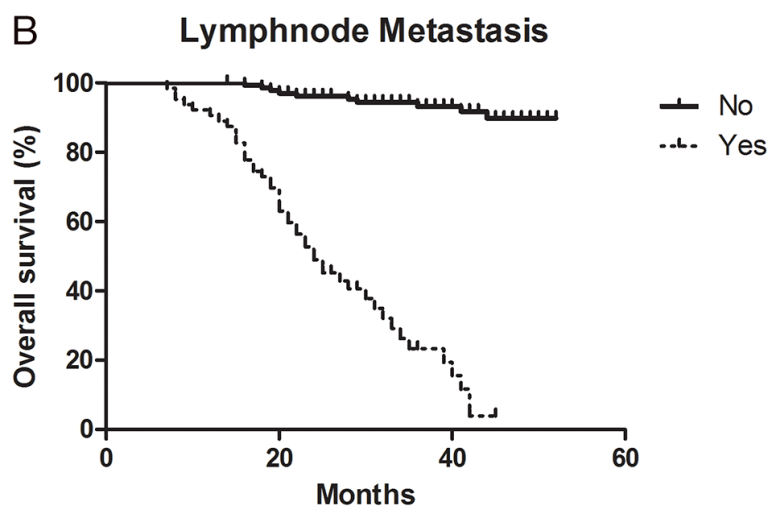

Figure 3: Overall survival curves for cervical cancer. (A) The overall survival rate of patient between small tumor $(\leq 4 \mathrm{~cm})$ and large tumor $(>4 \mathrm{~cm})$. (B) The overall survival rate of patient with or without lymphnode metastasis. 
Table 3: AUC of different combinations for diagnosing cervical cancer

\begin{tabular}{ll}
\hline & AUC \\
\hline Univariate & \\
CEA & 0.55 \\
CA125 & 0.62 \\
SCCA & 0.65 \\
MicroRNA-466 & 0.48 \\
Multivariate & \\
CEA+CA125 & 0.71 \\
CEA+SCCA & 0.70 \\
CA125+SCCA & 0.75 \\
CEA+CA125+SCCA & 0.80 \\
CEA+CA125+SCCA+ & 0.85 \\
MicroRNA-466 & \\
\hline
\end{tabular}

AUC: area under the receiver-operator curve; CEA: carcinoembryonic antigen; CA125: cancer antigen 125; SCCA: squamous cell carcinoma antigen.

highly expressed in cervical adenocarcinoma. SCCA was relatively specific for cervical squamous carcinoma. Another study showed that elevated SCCA levels were associated with lymph node metastasis among high-risk factors [27]. However, our study showed AC was more prone to lymph node metastasis than SCC $(P=0.039)$.

The gene of microRNA-466 is located on the short arm of the third chromosome (3p23). MicroRNA-466, first discovered from melanoma in 2010 [28], has been declared as a marker of lung cancer caused by smoking [29]. Genome sequence analysis and bioinformatics prediction indicate that microRNA-466 is highly homologous with the LCR region prediction miRNA of HPVl6/18, while the LCR region is the regulatory region of carcinogenic key protein expression [30]. Lots of evidence has shown that high-risk type HPV (HPV16/18) infection is a prominent risk factor for cervical cancer development [31]. MiRNAs may act as a bio-marker in cervical cancer tissue or cervical lesions which are related to HPV16/18 infection $[32,33]$. The expression of microRNA-466 in cervical cancer group was significantly greater than in normal people group. It was suggested that microRNA-466 might play a part in the pathogenesis cervical cancer progression.

Our study was designed to diagnose cervical cancer at the primary stage. The multivariate analysis of ROC curve was carried out to assess the value of various combinations of three tumor markers for the diagnosis of cervical cancer. Our results showed that the AUC for objective tumor markers was all below 0.7. Using a combination of tumor markers and microRNA-466, the AUC can reach 0.85 . One crucial question was why the combination correlates with the diagnosis levels of cervical cancer. Unfortunately, the answer for this question was outside the scope of the present investigation. The biologic functions of tumor markers were largely unknown and must be elucidated to respond to this question in the future [27]. The combination of the three tumor markers can be utilized to screening. On multivariate analysis of the ROC in the present study, it was difficult to ascertain the cut-off level for each tumor marker. Therefore, we used the cut-off levels recommended by the manufacturers of the test kits.

In conclusion, our results indicate that the new combination of serum tumor markers and microRNA-466 is closely associated to the occurrence and development of cervical cancer and can be utilized to screening for cervical cancer.

\section{MATERIALS AND METHODS}

\section{Samples and clinical data}

A total of 735 patients were recruited for this study at Affiliated Cancer Hospital of Zhengzhou University from January 2013 to June 2016. They were divided into three groups by pathology, namely normal group $(n=210)$, hyperplasia group $(\mathrm{n}=280)$, and cervical cancer group $(\mathrm{n}=245)$. The median age of the 735 patients was 49 years old (ranging from 26 to 72 years old). The selection criteria for patients were as follows: (1) pathologically confirmed patients with cervical cancer, cervical hyperplasia, or normal; (2) the patients had no history of other cancers; (3) No patients had prior treatment history. All the patients were reviewed by microRNA-466 and tumor markers (CEA, CA125 and SCCA) in serum levels. This study was subject to approval by the Ethics Committee of Affiliated Cancer Hospital of Zhengzhou University. All participants had a written informed consent which was consulted on all subjects. We confirmed that all methods were performed in accordance with the applicable guidelines and regulations. All identifying information of the patient had been removed from all text/figures/tables/images.

\section{Tumor markers analysis}

Electro-chemiluminescent immunoassay was used to identify the CEA and CA125 levels in serum using an automatic Roche Cobas E602 analyzer (Roche Diagnostics, Indianapolis, IN). The limit of detection was established by analyzing 10 replicates of the zero calibrators and 4 replicate of the lowest nonzero calibrator. The limit of detection for CEA and CA125 in human serum was determined to be $0.2 \mathrm{ng} / \mathrm{ml}$ and 0.50 $\mathrm{U} / \mathrm{ml}$, respectively. SCCA was monitored by enzyme immunoassay. The cut-off levels recommended by the manufacturers of the test kits were used. That is, $3.5 \mathrm{ng} / \mathrm{mL}$ for CEA, $35 \mathrm{U} / \mathrm{ml}$ for CA125, and $2.2 \mathrm{ng} / \mathrm{ml}$ for SCCA. 


\section{RNA extraction and quantitative real-time polymerase chain reaction}

The microRNA-466 was performed by quantitative real-time polymerase chain reaction. Total RNA was extracted and isolated from serum by using Trizol Reagent (Shanghai Sangon) according to the manufacturer's instructions. All the RNA was reverse-transcribed using the PrimeScript ${ }^{\circledR}$ RT reagent Kit (TaKaRa). The PCR conditions were as follows: $37^{\circ} \mathrm{C}$ for $15 \mathrm{~min}, 85^{\circ} \mathrm{C}$ for $5 \mathrm{~s}$, and $4{ }^{\circ} \mathrm{C}$ for preservation. MiRNA quantification was performed as described for the Applied Biosystems real-time PCR system using stem-loop primers for microRNA-466. RT-qPCR using SYBR ${ }^{\circledR}$ Premix Ex Taq $^{\text {TM }}$ II kit (TaKaRa). The PCR amplification conditions were as follows: $94^{\circ} \mathrm{C}$ denaturation for $2 \mathrm{~min}, 94^{\circ} \mathrm{C}$ for $15 \mathrm{sec}, 57^{\circ} \mathrm{C}$ for $20 \mathrm{sec}, 72^{\circ} \mathrm{C}$ for $15 \mathrm{sec}, 35 \mathrm{cycles}$. The expression level of microRNA-466 was calculated by comparative cycle threshold $(\mathrm{Ct})$ method. U6 was selected as internal control since its expression levels were stable in both patients with cervical cancer and non-cancer controls, and the $\mathrm{Ct}$ value of miR-466 was normalized in relation to that of U6. For calculations of fold changes we used the 2- $\Delta \Delta \mathrm{CT}$ method. Primer sequences are listed in Table 3 . The microRNA-466 cut-off level recommended by normal people was 0.1 .

\section{Statistical analysis}

All statistical analyses were performed using SPSS 17.0 statistical packages for Windows (SPSS Inc., Chicago, IL, USA). All values were presented as M (Mean) \pm SEM (Standard Error of Mean). The Student's t-test analysis was carried out to analyze the clinical data. Overall survival curves were used to assess the prognosis of cervical cancer. Areas under receiver operator curves (AUC) were estimated using a logistic regression model. All $P$-values were two-sided, and $P \leq 0.05$ was deemed to indicate statistical significance.

\section{Author contributions}

Li-Li Zhou and Yong Shen conceived the study designs and drafted the manuscript. Jiao-Mei Gong, Ping Sun and Jia-He Sheng carried out the study and performed the statistical analysis. All the authors participated in the discussion, provided conceptual input, and have read and agreed to the final manuscript.

\section{ACKNOWLEDGMENTS}

This work was supported by Henan Health and Planning Commission (No. 201404042) and Nursery Fund (3101030102). The authors thank the skillful technical assistance of Xi-Tian Hong.

\section{CONFLICTS OF INTEREST}

The authors declare no conflicts of interest.

\section{REFERENCES}

1. Gong JM, Shen Y, He YX, Lei DM, Zhang Z, Li XF. New technology for cervical cancer screening. Int J Gynecol Cancer. 2012; 22: 1564-9. https://doi.org/10.1097/ IGC.0b013e318272e7e7.

2. Arbyn M, Walker A, Meijer CJ. HPV-based cervical-cancer screening in China. Lancet Oncol. 2010; 11: 1112-3. https:// doi.org/10.1016/S1470-2045(10)70262-X.

3. Arbyn M, Castellsague X, de Sanjose S, Bruni L, Saraiya M, Bray F, Ferlay J. Worldwide burden of cervical cancer in 2008. Ann Oncol. 2011; 22: 2675-86. https://doi. org/10.1093/annonc/mdr015.

4. Hernandez-Hernandez DM, Apresa-Garcia T, Patlan-Perez RM. [Epidemiological overview of uterine cervical cancer]. [Article in Spanish]. Rev Med Inst Mex Seguro Soc. 2015; 53: S154-61.

5. Ambros V. The functions of animal microRNAs. Nature. 2004; 431: 350-5. https://doi.org/10.1038/nature02871.

6. Shen Y, Gong JM, Zhou LL, Sheng JH. MiR-451 as a new tumor marker for gastric cancer. Oncotarget. 2017; 8: 56542-56545. https://doi.org/10.18632/oncotarget.17239.

7. Pedroza-Torres A, Fernandez-Retana J, Peralta-Zaragoza O, Jacobo-Herrera N, Cantu de Leon D, Cerna-Cortes JF, Lopez-Camarillo C, Perez-Plasencia C. A microRNA expression signature for clinical response in locally advanced cervical cancer. Gynecol Oncol. 2016; 142: 55765. https://doi.org/10.1016/j.ygyno.2016.07.093.

8. Zhang L, Huang J, Yang N, Greshock J, Megraw MS, Giannakakis A, Liang S, Naylor TL, Barchetti A, Ward MR, Yao G, Medina A, O'Brien-Jenkins A, et al. microRNAs exhibit high frequency genomic alterations in human cancer. Proc Natl Acad Sci U S A. 2006; 103: 9136-41. https://doi.org/10.1073/pnas.0508889103.

9. Yang Y, Song KL, Chang H, Chen L. Decreased expression of microRNA-126 is associated with poor prognosis in patients with cervical cancer. Diagn Pathol. 2014; 9: 220. https://doi.org/10.1186/s13000-014-0220-X.

10. $\mathrm{Li} \mathrm{MY}, \mathrm{Hu} \mathrm{XX}$. Meta-analysis of microRNA expression profiling studies in human cervical cancer. Med Oncol. 2015; 32: 510. https://doi.org/10.1007/ s12032-015-0510-5.

11. Sun P, Shen Y, Gong JM, Zhou LL, Sheng JH, Duan FJ. A new microRNA expression signature for cervical cancer. Int J Gynecol Cancer. 2017; 27: 339-43. https://doi. org/10.1097/IGC.0000000000000863.

12. Seckin KD, Karsli MF, Yucel B, Bestel M, Yildirim D, Canaz E, Akbayir O. The utility of tumor markers and neutrophil lymphocyte ratio in patients with an intraoperative diagnosis of mucinous borderline ovarian 
tumor. Eur J Obstet Gynecol Reprod Biol. 2016; 196: 60-3. https://doi.org/10.1016/j.ejogrb.2015.10.025.

13. Kotowicz B, Fuksiewicz M, Jonska-Gmyrek J, Bidzinski M, Kowalska M. The assessment of the prognostic value of tumor markers and cytokines as SCCAg, CYFRA 21.1, IL-6, VEGF and sTNF receptors in patients with squamous cell cervical cancer, particularly with early stage of the disease. Tumour Biol. 2016; 37: 1271-8. https://doi. org/10.1007/s13277-015-3914-0.

14. Shah UA, Saif MW. Tumor markers in pancreatic cancer: 2013. JOP. 2013; 14: 318-21.

15. Farzaneh F, Shahghassempour S, Noshine B, Arab M, Yaseri M, Rafizadeh M, Alizadeh K. Application of tumor markers SCC-Ag, CEA, and TPA in patients with cervical precancerous lesions. Asian Pac J Cancer Prev. 2014; 15: 3911-4.

16. Zamani N, Modares Gilani M, Zamani F, Zamani MH. Utility of pelvic MRI and tumor markers HE4 and CA125 to predict depth of myometrial invasion and cervical involvement in endometrial cancer. J Family Reprod Health. 2015; 9: 177-83.

17. Diaz J, Yu D, Micaily B, Ferriss JS, Hernandez E. Radiation therapy with concurrent chemotherapy for locally advanced cervical carcinoma: outcome analysis with emphasis on the impact of treatment duration on outcome. Obstet Gynecol Int. 2014; 2014: 214351. https:// doi.org/10.1155/2014/214351.

18. Bian J, Sun X, Li B, Ming L. Clinical significance of serum HE4, CA125, CA724, and CA19-9 in patients with endometrial cancer. Technol Cancer Res Treat. 201. https:// doi.org/10.1177/1533034616666644.

19. Amiri FS. Serum tumor markers in chronic kidney disease: as clinical tool in diagnosis, treatment and prognosis of cancers. Ren Fail. 2016; 38: 530-44. https://doi.org/10.31 09/0886022X.2016.1148523.

20. Sturgeon CM, Duffy MJ, Hofmann BR, Lamerz R, Fritsche HA, Gaarenstroom K, Bonfrer J, Ecke TH, Grossman HB, Hayes P, Hoffmann RT, Lerner SP, Lohe F, et al. National Academy of Clinical Biochemistry Laboratory Medicine Practice Guidelines for use of tumor markers in liver, bladder, cervical, and gastric cancers. Clin Chem. 2010; 56: e1-48. https://doi.org/10.1373/clinchem.2009.133124.

21. Gold P, Freedman SO. Demonstration of tumor-specific antigens in human colonic carcinomata by immunological tolerance and absorption techniques. J Exp Med. 1965; 121: 439-62.

22. Chmura A, Wojcieszek A, Mrochem J, Walaszek-Gruszka A, Deja R, Maslyk B, Bartnik W, Sodowski K. [Usefulness of the SCC, CEA, CYFRA 21.1, and CRP markers for the diagnosis and monitoring of cervical squamous cell carcinoma]. [Article in Polish]. Ginekol Pol. 2009; 80: 361-6.

23. Volgger B, Aspisirengil C, Genser-Krimbacher E, CiresaKoenig A, Daxenbichler G, Fuchs D, Windbichler G,
Marth C. Prognostic significance of TPA versus SCC-Ag, CEA and neopterin in carcinoma of the uterine cervix. Cancer Lett. 2008; 262: 183-9. https://doi.org/10.1016/j. canlet.2007.12.005.

24. Yang ZJ, Zhao BB, Li L. The significance of the change pattern of serum CA125 level for judging prognosis and diagnosing recurrences of epithelial ovarian cancer. J Ovarian Res. 2016; 9: 57. https://doi.org/10.1186/ s13048-016-0266-3.

25. Tsai CC, Liu YS, Huang EY, Huang SC, Chang HW, Tseng $\mathrm{CW}$, ChangChien CC. Value of preoperative serum CA125 in early-stage adenocarcinoma of the uterine cervix without pelvic lymph node metastasis. Gynecol Oncol. 2006; 100: 591-5. https://doi.org/10.1016/j.ygyno.2005.09.049.

26. Xiong Y, Peng XP, Liang LZ, Zheng M, Li JD. Clinical significance of combined examination of pretreatment serum CYFRA21-1 and SCCAg in cervical cancer patients. Ai Zheng. 2009; 28: 64-7.

27. Ikeda S, Yoshimura K, Onda T, Kasamatsu T, Kato T, Ishikawa M, Sasajima Y, Tsuda H. Combination of squamous cell carcinoma-antigen, carcinoembryonic antigen, and carbohydrate antigen 19-9 predicts positive pelvic lymph nodes and parametrial involvement in early stage squamous cell carcinoma of the uterine cervix. J Obstet Gynaecol Res. 2012; 38: 1260-5. https://doi. org/10.1111/j.1447-0756.2012.01862.x.

28. Stark MS, Tyagi S, Nancarrow DJ, Boyle GM, Cook AL, Whiteman DC, Parsons PG, Schmidt C, Sturm RA, Hayward NK. Characterization of the melanoma miRNAome by deep sequencing. PLoS One. 2010; 5: e9685. https://doi.org/10.1371/journal.pone.0009685.

29. Izzotti A, Larghero P, Longobardi M, Cartiglia C, Camoirano A, Steele VE, De Flora S. Dose-responsiveness and persistence of microRNA expression alterations induced by cigarette smoke in mouse lung. Mutat Res. 2011; 717: 9-16. https://doi.org/10.1016/j.mrfmmm.2010.12.008.

30. Gu W, An J, Ye P, Zhao KN, Antonsson A. Prediction of conserved microRNAs from skin and mucosal human papillomaviruses. Arch Virol. 2011; 156: 1161-71. https:// doi.org/10.1007/s00705-011-0974-3.

31. Mo W, Tong C, Zhang Y, Lu H. microRNAs' differential regulations mediate the progress of Human Papillomavirus (HPV)-induced Cervical Intraepithelial Neoplasia (CIN). BMC Syst Biol. 2015; 9: 4. https://doi.org/10.1186/ s12918-015-0145-3.

32. Gocze K, Gombos K, Kovacs K, Juhasz K, Gocze P, Kiss I. MicroRNA expressions in HPV-induced cervical dysplasia and cancer. Anticancer Res. 2015; 35: 523-30.

33. Yang Y, Xie YJ, Xu Q, Chen JX, Shan NC, Zhang Y. Downregulation of miR-1246 in cervical cancer tissues and its clinical significance. Gynecol Oncol. 2015; 138: 683-8. https://doi.org/10.1016/j.ygyno.2015.06.015. 